\title{
PENILAIAN PRODUK KANCING BERBENTUK HURUF DENGAN BAHAN DASAR LIMBAH STYROFOAM ABSTRACT
}

The research aims to find out the assessment of Styrofoam Letter-Shaped Button Products full colour theme, Rainbow inspiration source, style and look sporty off beat which is assessed based on product quality theory and design

Fika Fiqratul Aulia ${ }^{1}$

E.Lutfia Zahra²

Dewi Suliyanthini ${ }^{3}$

\section{Afiliasi \\ ${ }^{123}$ Pendidikan Tata Busana, Universitas Negeri Jakarta}

Contributor email :

1fika.perahu@yahoo.com element theory and design principles. Descriptive qualitative research methods. By measuring based on aspects of comfort, benefits, the shape of the center of attention color and the element of design. Valued by 5 panelists. The results of the button accessories research has a design element of color shape texture was quite good. And can be used as a button for children's clothing. But in performance it takes a more perfect improvement process.

Keywords. : button accessories. Waste styaroam.

\section{ABSTRAK}

Penelitian bertujuan untuk mengetahui penilaian Produk Kancing Berbentuk Huruf Berbahan Dasar Styrofoam tema full colour, Sumber inspirasi Pelangi, style and look sporty off beat yang dinilai berdasarkan teori kualitas produk dan teori unsur desain dan prinsip desain. Metode penelitian kualitatif deskriptif. Dengan mengukur berdasarkan aspek kenyamanan, manfaat, bentuk warna pusat perhatian dan unsur disain. yang di nilai oleh 5 panelis. Hasil penelitian asesoris kancing memiliki unsur desain bentuk warna tekstur yang cukup baik. Dan dapat digunakan sebagai kancing busana anak. Namun dalam performance diperlukan proses penyempurnaan lebih sempurna.

Kata Kunci. : Asesoris Kancing. Limbah Styaroam.

\section{A. PENDAhuluan}

Anak usia dini merupakan masa peka seorang anak terhadap suatu lingkungan, baik lingkungan keluarga maupun lingkungan sekolah. Masa ini adalah masa awal dalam mengembangkan potensi yang ada pada diri anak. perkembangan atau biasanya yang sering disebut masa golden age. Masa golden age adalah masa perkembangan yang harus dimanfaatkan bagi pendidikdan juga bagi orangtua.Dalam hal ini belajar sangat dianjurkan guna membangun pengetahuan anak, terutama dalam hal pengetahuan mengenal huruf agar anak mampu dan memahami macam-macam huruf. Maka dari itu, Peran pendidik sangatlah penting dalam meningkatkan kemampuan mengenal huruf bagi anak.

Styrofoam merupakan salah satu pilihan yang paling popular untuk digunakan sebagai pengemas barang-barang yang rentan rusak maupun makanan sekalipun. Styrofoam memiliki keunggulan yaitu praktis dan tahan lama. Hal inilah yang menjadi daya tarik yang cukup kuat bagi para penjual maupun konsumen makanan untuk menggunakannya. Sampai saat ini belum banyak yang sadar bahaya dibalik penggunaan kemasan styrofoam.

Berdasar kajian, jika dipakai berlebih dan jadi kemasan makanan dan minuman akan berakibat adanya semacam zat yang akan bersenyawa dengan makanan (karsinogen) itu berbahaya bagi kesehatan. Dampak masalah yang mudah ditemui, yaitu tersumbatnya 
aliran air di parit hingga sungai yang berakibat meluapnya air sungai, dampak singkatnya terjadi banjir

Penggunaan styrofoam untuk wadah makanan bakal dibatasi di Kota Bogor. Hal itu disampaikan Wali Kota Bogor, bima arya usai menyusuri 2 Sungai Ciliwung menggunakan perahu karet beberapa waktu lalu. Bima menyebut, secara keseluruhan titik penumpukan sampah relatif berkurang. Dia menegaskan lebih banyak sampah yang dibawa dari hulu dan mayoritas jenisnya styrofoam.

Adanya penumpukkan sampah Styrofoam yang mengganggu aliran sungai Ciliwung kondisi tersebut perlu ada pengurangan dengan cara memanfaatkan limbah Styrofoam untuk menjadikan suatu media pengenalan huruf pada anak. Dalam penelitian ini peneliti tertarik untuk membuat kancing berbentuk huruf berbahan dasar Styrofoam. Dengan adanya kancing hias berbentuk huruf berbahan dasar Styroam ini dapat memudahkan anak dalam mengenal huruf segaligus mengenalkan bagaimana cara memanfaatkan sampah Styrofoam.

\section{B. METODE}

Penelitian ini bertujuan untuk penilaian produk kancing hias berbahan dasar limbah styrofoam, berdasarkan teori penilaian produk W.H Mayall dan David A Garvin yang mencakup bentuk yang beragam, kenyamanan, keamanan, penampilan dan comformance. Produk juga akan dinilai melalui aspek unsur dan prinsip desain oleh Catri Sumaryati, berdasarkan unsur desain yakni bentuk, warna, tekstur dan ukuran. Sedangkan berdasarkan aspek prinsip desain adalah ; prinsip desain, proporsi dan pusat perhatian. Tempat penelitian di lakukan di laboratorium program studi Tata Busana, Fakultas Teknik,Universitas Negeri Jakarta.

Penelitian di lakukan pada semester ganjil tahun akademik 2020. Metode yang digunakan dalam penelitian ini adalah metode penelitian deskriptif dengan pendekatan kualitatif. Peneliti menggunakan pendekatan kualitatif karena dengan pendekatan ini, peneliti dapat menggali data dan informasi lebih mendalam mengenai produk yang akan dibuat. Penelitian kualitatif adalah penelitian yang dinyatakan dalam bentuk verbal dan dianalisis tanpa menggunakan teknik statistik. (Sangadji \& Sopiah, 2010 : 24). Deskriptif digunakan untuk membantu pembaca mengetahui apa yang terjadi di 51 lingkungan bawah penelitian, seperti apa pandangan yang berada di latar penilitian dan seperti apa peristiwa atau aktifitas yang yang terjadi di latar penelitian. (Gezuk, 2003: 7-8).

Definisi wawancara menurut Estenberg (2002) adalah pertemuan dua orang untuk bertukar informasi dan ide melalui tanya jawab, sehingga dapat dikonstruksikan makna dalam suatu topik tertentu. Peneliti menggunakan wawancara terstruktur, karena telah mengetahui dengan pasti informasi yang akan diperoleh. Dengan waawancara terstruktur setiap responden diberikan pertanyaan yang sama dan pengumpul data mencatatnya (Sugiyono, 2014 : 233). Dalam penelitian ini, peneliti akan melakukan wawancara kepada beberapa informan 62 yang akan memberikan penilaian pada produk yang akan diteliti. Informan dipilih berdasarkan karakteristik yang telah ditentukan oleh peneliti, yaitu orang yang memiliki pegetahuan serta pengalaman dibidang yang akan dinilai. 5 informan antara lain:

1. Winda Rostianti Guru TK di TK Melati

2. Silfy Salwa Guru TK di TK At-taqwa

3. Ardi Manager di GEMA Busana Anak

4. Agus Salim Aktivis Lingkungan di Bank Sampah Bogor

2 |Practice of Fashion and Textile Education Journal; vol 1, № 1. 
5. Ervan Timtim Pemilik Perusahaan PT.Indo Bhineka Ervasatya produsen kancing ukir Dalam penelitian kualitatif, analisis data dilaksanakan sebelum peneliti terjun ke lapangan, selama peneliti mengadakan penelitian di lapangan, sampai dengan pelaporan hasil penelitian. Analisis data dimulai sejak peneliti menentukan fokus penelitian sampai dengan pembuatan laporan penelitian selesai. Jadi teknik analisis data dilaksanakan sejak merencanakan penelitian sampai penelitian selesai. Analisis data adalah proses mencari dan menyusun secara sistematis data yang diperoleh dari hasil wawancara, catatan lapangan, dan 64 bahan- bahan lain, sehingga dapat mudah dipahami, dan temuannya dapat diinformasikan kepada orang lain. Analisis data dilakukan dengan mengorganisasikan data, menjabarkannya ke dalam unit - unit, melakukan sintesa, menyusun ke dalam 93 pola, memilih mana yang penting dan yang akan dipelajari, dan membuat kesimpulan yang dapat diceritakan kepada orang lain (Sugiyono, 2007:224)

Triangulasi dapat diartikan sebagai teknik pengumpulan data yang bersifat menggabungkan dari berbagai teknik pengumpulan data dan sumber data yang telah ada. Bila peneliti melakukan pengumpulan data dengan triangulasi, maka sebenarnya peneliti mengumpulkan data yang sekaligus menguji kredibilitas data, yaitu mengecek kredibilitas data dengan berbagai teknik pengumpulan data dan berbagai sumber data (sugiyono, 2014:330). Triangulasi dapat diartikan sebagai teknik pengumpulan data yang bersifat menggabungkan dari berbagai teknik pengumpulan data dan sumber data yang telah ada. Bila peneliti melakukan pengumpulan data dengan triangulasi, maka sebenarnya peneliti mengumpulkan data yang sekaligus menguji kredibilitas data, yaitu mengecek kredibilitas data dengan berbagai teknik pengumpulan data dan berbagai sumber data (sugiyono, 2014:330). Triangulasi sumber adalah triangulasi yang digunakan untuk menguji kredibilitas data dengan cara mengecek data yang telah diperoleh melalui beberapa sumber. Pada penelitian ini peneliti menggunakan tringulasi sumber, dimana peneliti akan menguji kredibilitas data dengan mengecek data yang telah diperoleh melalui beberapa panelis ahli.

\section{HASIL DAN PEMBAHASAN}

Berdasarkan hasil wawancara yang dilakukan oleh peneliti kepada kelima panelis ahli mengenai penggunaan limbah Styrofoam sebagai produk dengan berbahan dasar kancing yang berbentuk huruf yang melalui proses penghancuran dengan menggunakan aseton rosary diberikan macam-macam warna dan dibentuk menggunakan cetakan huruf dengan berbagai macam ukuran akan di lihat berdasarkan teori penilaian produk dan unsur desain. Indicator yang digunakan yaitu meliput kemudahan dan kenyamanan, keistimewaan yang dimiliki produk, estetika produk. Berikut adalah pemaparan berdasarkan dari hasil wawancara dengan panelis ahli yang dikaitkan dengan teori yang sesuai dengan penelitian.

Berdasarkan fakta hasil wawancara mengenai karakteristik pada produk, Menurut Mullins, Orville. Larreche, dan Boyd, (performance) Kinerja merupakan karakteristik atau fungsi utama suatu produk. Ini merupakan manfaat atau khasiat utama produk yang kita beli. Biasanya ini menjadi pertimbangan pertama kita membeli produk.

Dari uraian fakta diatas dan dikaitkan dengan teori yang ada bahwa menurut kelima panelis mengenai kenyamanan dan kemudahan yang dihasilkan dari limbah Styrofoam, empat panelis setuju bahwa Styrofoam bisa di daur ulang menjadi sebuah kancing huruf, Satu panelis (P3) menyatakan tekstur alami pada Styrofoam yang di cairkan kurang licin dan masih sedikit kasar sehingga menyulitkan anak dalam pemasangan.dan penelis (P4) menyatakan bahwa bentuk kancing sulit untuk digunakan anak, dan memberikan masukan 
agar peneliti menggunakan snap sebagai pengganti kancing yang menggunakan lubang . gunanya agar kancing bisa tetap di aplikasikan di pakaian anak tetapi tetap mudah saat di gunakan.

Berdasarkan fakta hasil wawancara mengenai Features (fitur), dapat dikaitkan dengan teori Features (fitur) adalah karakteristik produk yang dirancang untuk menyempurnakan fungsi produk atau menambah ketertarikan konsumen 84 terhadap produk. Dimensi fitur merupakan karakteristik atau ciri-ciri tambahan yang melengkapi manfaat dasar suatu produk. Fitur bersifat pilihan atau option bagi konsumen. Kalau manfaat utama sudah standar, fitur seringkali ditambahkan. Idenya, fitur bisa meningkatkan kualitas produk kalau pesaing tidak memiliki.

Dari uraian diatas dan dikaitkan dengan teori yang ada maka produk kancing huruf yang berbahan dasar Styrofoam ini menurut keempat panelis keistimewaan dari kancing huruf ini adalah berbahan dasar Styrofoam yang di diolah kembali menjadi sebuah produk, sedangkan 1 panelis lebih memilih bentuk huruf yang menjadi keistimewaan dari kancing huruf yang berbahan dasar styrofoam.

Berdasarkan fakta hasil wawancara mengenai Durability (daya tahan), yang berarti berapa lama atau umur produk yang bersangkutan bertahan sebelum produk tersebut harus diganti. Semakin besar frekuensi pemakaian konsumen terhadap produk maka semakin besar pula daya tahan produk..

Dari uraian diatas dan dikaitkan dengan teori yang ada bahwa menurut kelima panelis mengenai ketahanan kancing huruf, ke 3 panelis (P2,P3, dan P4) mengatakan kekuatan kancing masih kurang dan masih mudah patah. Dan satu panelis (P1) mengatakan bahwa kancing tersebut ketahanannya cukup kuat karna telah melalui proses pencairan, sedangkan panelis ke 4 memberikan saran untuk lebih memperhatikanlagi kaandungan dari aseton itu aman atau tidaknya untuk anak anak, atau bisa mencari metode cara penghancur styrofoam yang sifatnya foodgrade

Berdasarkan fakta hasil wawancara mengenai Aesthetics (estetika), berhubungan dengan bagaimana penampilan produk bisa dilihat dari tampak, rasa, bau, dan bentuk dari produk. Dari uraian data diatas dan dikaitkan dengan teori yang ada bahwa menurut keempat mengenai estetika kancing huruf, ke 4 panelis mengatakan penampulan bentuk kancing huruf bagus dan sesuai.

Berdasarkan hasil wawancara yang dilakukan oleh peneliti kepada kelima panelis ahli mengenai penggunaan limbah Styrofoam sebagai produk dengan berbahan dasar kancing yang berbentuk huruf yang melalui proses penghancuran dengan menggunakan aseton rosary diberikan macam-macam warna dan dibentuk menggunakan cetakan huruf dengan berbagai macam ukuran akan di lihat berdasarkan teori estetika desain meliputi unsur desain dan prinsip desain. Indikator unsur desain yang digunakan yaitu bentuk, ukuran dan warna. Berikut adalah pemaparan berdasarkan dari hasil wawancara dengan panelis ahli yang dikaitkan dengan teori yang sesuai dengan penelitian.

Berdasarkan fakta hasil wawancara mengenai unsur desain bentuk, dapat dikaitkan dengan teori unsur desain bentuk bentuk dapat dikaitkan dengan teori unsur bentuk desain menurut Soekarno \& Lanawati Basuki (2004:12) membuat desain tidak hanya berlandaskan ide, tetapi juga harus mempunyai konsep rancangan bentuk dasar yang mudah dipahami. Konsep rancangan bentuk dasar ini dituangkan ke dalam bentuk pola rancangan sehingga mudah diwujudkan dalam bentuk yang sebenarnya.dalam hal ini bentuk disesuaikan dengan bentuk huruf yang alami.

4 |Practice of Fashion and Textile Education Journal; Vol 1, No 1. 
Dari uraian diatas dan dikaitkan dengan teori yang ada bahwa menurut kelima panelis mengenai bentuk kancing huruf dari limbah styrofoam, semua panelis mengatakan bentuk kancing bagus hanya saja satu panelis (P3) kurang setuju dengan bentuk huruf I dan $j$, panelis 5 , memberikan saran kancing huruf untuk dijadikan kancing snap untuk memudahkan saat digunakan.

Berdasarkan fakta hasil wawancara mengenai unsur desain ukuran, dapat dikaitkan dengan teori unsur desain ukuran dalam dunia desain dapat memberikan penekananpenekanan tertentu dari sebuah besar-kecilnya sebuah objek. Besar kecilnya sebuah ukuran dapat memberikan kemudahan bagi para pembaca dalam memilih sebuah informasi yang dianggap penting karena secara tidak langsung pembaca dapat langsung diarahkan kesuatu objek dengan penekanan- penekanan tertentu.

Dari uraian diatas dan dikaitkan dengan teori yang ada bahwa menurut kelima panelis hiasan yang menyatakan ukuran kancing huruf yang dibuat sudah cukup pas dan sesuai untuk diaplikasikan pada busana anak hanya ada dua panelis yang meminta dibuatkan ukuran yang lebih besar lagi untuk dijadikan permainan anak

Berdasarkan fakta hasil wawancara mengenai unsur desain warna, dapat dikaitkan dengan teori unsur warna dapat didefinisikan secara obyektif/fisik sebagai sifat cahaya yang dipancarkan, atau secara subyektif/psikologis sebagai bagian dari pengalaman indera penglihatan. Secara obyektif atau fisik, warna dapat diberikan oleh panjang gelombang. Dilihat dari panjang gelombang, cahaya yang tampak oleh mata merupakan salah satu bentuk pancaran energi yang merupakan bagian yang sempit dari gelombang elektromagnetik.

Warna mempunyai fungsi untuk memperkuat aspek identitas. Lebih lanjut dikatakan oleh Henry Dreyfuss, bahwa warna digunakan dalam simbol-simbol grafis untuk mempertegas maksud dari simbol- simbol tersebut. Sebagai contoh adalah penggunaan warna merah pada segitiga pengaman, warna- warna yang digunakan untuk traffic light merah untuk berhenti, kuning untuk bersiap- siap dan hijau untuk jalan. Dari contoh tersebut ternyata pengaruh warna mampu memberikan impresi yang cepat dan kuat. Kemampuan warna menciptakan impresi, mampu menimbulkan efek-efek tertentu. Secara psikologis diuraikan oleh J. Linschoten dan Drs. Mansyur tentang warna sebagai berikut : Warnawarna itu bukanlah suatu gejala yang hanya dapat diamati saja, warna itu mempengaruhi.

Dari uraian data diatas dan dikaitkan dengan teori yang ada bahwa menurut kelima panelis mengenai warna kancing huruf berbahan dasar styrofoam, keempat panelis menyatakan warna kancing huruf yang dibuat cerah dan dapat menarik perhatian anak, dan panelis ke 5 memberikan saran untuk mencari metode baru agar membuat warna kancing yang bening

Berdasarkan hasil wawancara yang dilakukan oleh peneliti kepada kelima panelis ahli mengenai penggunaan limbah Styrofoam sebagai produk dengan berbahan dasar kancing yang berbentuk huruf yang melalui proses penghancuran dengan menggunakan aseton rosary diberikan macam-macam warna dan dibentuk menggunakan cetakan huruf dengan berbagai macam ukuran akan di lihat berdasarkan teori estetika desain meliputi unsur desain dan prinsip desain. Indikator prinsip desain yang digunakan yaitu proporsi, keseimbangan,Berikut adalah pemaparan berdasarkan dari hasil wawancara dengan panelis ahli yang dikaitkan dengan teori yang sesuai dengan penelitian.

Berdasarkan fakta hasil wawancara mengenai prinsip desain proporsi dapat dikaitkan dengan teori prinsip desain proporsi merupakan hubungan perbandingan antara 
bagian dengan bagian lain atau bagian dengan elemen keseluruhan. Prinsip ini mengatur perbandingan dan komparasi objek dalam segi ukuran. Dengan kata lain, prinsip ini mengatur perubahan ukuran panjang, lebar, dan tinggi dari setiap objek yang ada pada karya seni. Prinsip ini lebih menekankan pada varisasi atau keragaman ukuran unsur yang satu dengan unsur yang lain dalam satu kesatuan yang utuh.

Dari uraian data diatas dan dikaitkan dengan teori yang ada bahwa menurut kelima panelis proprsi kancing huruf berbahan dasar styrofoam, keempat panelis menyatakan proporsi kancing huruf yang dibuat sudah cukup pas dan sesuai, hanya saja satu panelis (P3) menyatakan bahwa proporsi L,J,dan I proporsinya kurang pas.

Berdasarkan fakta hasil wawancara mengenai prinsip desain pusat perhatian Prinsip ini mengacu pada pemberian kepentingan khusus untuk satu atau bagian tertentu dari desain. Ada 1 objek utama yang menjadi fokus atau center of interest sebuah karya. Dengan kata lain, objek utama dalam sebuah karya seni lebih ditekankan atau ditonjolkan dibanding dengan objek penunjang lain. Caranya dengan pengaturan ukuran dan proporsi satu sama lain sehingga fokus utama dapat lebih ditonjolkan.

Dari uraian data diatas dan dikaitkan dengan teori yang ada bahwa menurut kelima panelis pusat perhatian kancing huruf berbahan dasar styrofoam, untuk produk semua panelis memilih ukuran dan warna yang berbeda. Panelis 3 menyatakan bahwa pusat perhatianyang ada pada kancing huruf ini adalah dari bahan dasarnya yang terbuat dari pengolahan limbah styrofoam, Sedangkan panelis 2 menyatakan bahwa yang menjadi pusat perhatian ialah bentuk kancing yang unik.

\section{KESIMPULAN}

Berdasarkan hasil penelitian yang telah di lakukan oleh peneliti dapat di ketahui bahwa proses pengolahan limbah Styrofoam yang di jadikan sebagai bahan dasar pembuatan kancing berbentuk huruf melalui beberapa tahapan, yaitu mulai dari pengumpulan limbah Styrofoam kemasan makanan dengan permukaan yang rata dan tidak berwarna sengga memeudahkan dalam proses pewarnaan. Hasil penilaian menurut informan, kancing berbentuk huruf dengan berbahan dasar Styrofoam berdasarkan penilaian produk yang ada dengan nilai tertinggi dari keistimewaan yang di miliki produk, manfaat produk, dan estetika produk. Sedangkan penilaian informan berdasarkan unsur desain yang meliputi ,bentuk, warna dan yang terakhir adalah ukuran, Dan penilaian informan berdasarkan prinsip Desain kancing berbentuk huruf berbahan dasar Styrofoam dinilai sudah memenuhu teori prinsip desain dengan nilai tertinggi dilihat dari prinsip desain pusat perhatian dan proporsi.kancing huruf ukuran paling kecil, besar, dan sedang Dinilai paling menarik perhatian disebabkan manfaat penggunaan dan warnanya Kancing berbebtuk huruf berbahan dasar Styrofoam dinilai sudah memenuhi nilai produk berdasarkam estetika, sehingga dapat disimpulkan bahwa kancing berbentuk huruf dengan memanfaatkan limbah, dinilai sudah cukup memenuhi penilaian produk berdasarkan manfaat dan estetica.

\section{E. DAFTAR PUSTAKA}

Arief, Latar Muhammad, (2016). Pengolahan Limbah Industri, Yogyakarta: CV ANDI OFFSET (Penerbit Andi).

Dosen Pendidikan,"Desain, Pengertian, Prinsip, Unsur, Jenis, Manfaat \& Contoh", (2020).7

(8) 11.18 .37 (dosenpendidikan.co.id) Desain - Pengertian, Prinsip, Unsur, Jenis, Manfaat \& Contoh ,

6 |Practice of Fashion and Textile Education Journal; vol 1, № 1. 
Fesye Design."Unsur-unsur Desain (Busana)", (2020). 19 (07)

www.fesyendesign.com Unsur-unsur Desain (Busana)

(https://fitinline.com/article/read/pelengkap- busana-yang-memiliki-unsurdekoratif-danunsur-fungsional/ (2020) 14 (05) 16.27.23

https://www.gurupendidikan.co.id/pengertia n-produk, (2020) 02 (08) 08.14 .13

https://www.haruspintar.com/prinsip-desain/ (2020) 25 (03) 09.42.46

"Pengertian Styrofoam", https://id.scribd.com/doc/47406734/Pengerti anstyrofoam (2020) 08 (08) 202008.52 .19

"Pengertian Produk", https://jagad.id/pengertian-produk (2020) 27 (07) 09.18 .43 "Studi Sampah Plastik Di Teluk Jakarta Didominasi Oleh Styrofoam", https://nationalgeographic.grid.id/read/1320 03950/

"Studi sampah plastikdi teluk Jakarta didominasi oleh Styrofoam" (2020) 25 (06)

10.04.43

"Styrofoam Untuk Bangunan Yang Gempa", https://peluangusaha.kontan.co.id/news/bata ko-styrofoam-untukbangunanyang-tahan- gempa--1 (2011) 06 (06) 202013.36 .23

"Pengerian Limbah Menurut Ahli Jenis Karakter dan Dampaknya", https://pendidikan.co.id/pengertian-limbah- menurut-ahli-jeniskarakteristik-dandampaknya (2021) 02 (02) 08.17.29

"Bahaya Styrofoam", https://rimbakita.com/bahaya-styrofoam (2020) diakses pada 16 (02) 09.42 .40

"Sejarah Terciptanya Kancing Baju", https://lifestyle.sindonews.com/read/130889 3/186/sejarah-terciptanyakancing-baju- 1527231483 (2018) 17 (09) 10.34.2693

Suliantiny, Cholilawati Dewi, (2019). Asesoris Kalung. Bandung: CV SADARI (Anggota IKAPI JABAR)

Sulistiyani,200.2015."Kancing

Hias", https://sulistiyani200.wordpress.com/2015/0 5/13/kancing-hias, diakses pada 16 (04) 08.22.17

https://sumberbelajar.belajar.kemdikbud.go.i d/sumberbelajar/tampil/Styrofoam2010/kont en1.html, di akses pada 28 (03) 202008.19 .27

http://www.terasedukasi.com/2013/03/peng ertian-penilaian-danunsurunsurnya.html?m=1, diakses pada 9 (05) 2020 pukul 14.43 WIB

Thegorbalsla."Limbah", https://thegorbalsla.com/limbah/, diakses pada 21 (06) 2020 pukul 09.28.34

Tinta Pendidikan Indonesi."Penilaian Produk", https://www.tintapendidikanindonesia.com/2 016/09/penilaianproduk.html, diakses pada 16 (10) 2020 pukul 10.37.23

Unisby." Microsoft Word-BAB II KU", Microsoft Word - BAB II KU versi outlet

(uinsby.ac.id), diakses pada 22 (06) 2020 pukul 10.29.54

Utami, V. G. (2015). Industri Kreatif. Jakarta : Lebaga Pengembangan Pendidikan Universitas Negeri Jakarta.

Yusuf, A Muri, 2016. Metode Penelitian Kuantitatif, Kualitatif \& Penelitian Gabungan. Jakarta: PT Fajar Interpratama Mandiri.

BAB I-V.pdf (unpas.ac.id) Purwaningsih, Esty (2006) 611-1371-1-PB.pdf (bsi.ac.id) MENGENAL WARNA, ANGKA, HURUF DAN BENTUK PADA ANAK USIA DINI MELALUI ANIMASI INTERAKTIF

Sungai Ciliwung Banyak Sampah, Penggunaan Styrofoam Bakal Dibatasi di Kota - News sariagri.id (2020) 2 (02) 14.17.23 
Umriatud, Damiati. UPAYA MENINGKATKAN KEMAMPUAN MENGENAL HURUF MELALUI PERMAINAN LEMPAR DADU DI TK SUNAN PRAPEN GRESIK Oleh: 195392393.pdf (core.ac.uk)

Yulianti2, Lies Lestari2. PENINGKATAN PENGENALAN HURUF MELALUI MODEL PEMBELAJARAN QUANTUM PADA ANAK KELOMPOK A TK 94 AL ISLAM 4 SURAKARTA

TAHUN AJARAN 2015 / 2016 Ganis Hapsari1 , 35357-88234-1-SM.pdf

Kiptiah, Mariatul. MENGENALKAN HURUF PADA ANAK KELOMPOK A TK BUNGA HARAPAN KABUPATEN TAPIN MELALUI

MODEL TALKING STICK Oleh: (Mahasiswa S1 PG PAUD Unlam) 2160-5938-1-SM (1).pdf

Nuraini, Rini. UPAYA MENINGKATKAN KECERDASAN KINESTETIK MELALUI KEGIATAN

MENARI LAGU TOKECANG (Penelitian Tindakan Kelas Terhadap Anak Usia Dini

Kelompok B TK Permata Ibu Cimahi) rinifafa@yahoo.com. 60-8359-1-PB.pdf

Kemampuan mengenal huruf . IAIN KENDARI BAB II.pdf (iainkendari.ac.id) (2020) 14 (06)

09.32 .54

13 Pengaruh Warna pada Psikologi Anak - DosenPsikologi.com (2020) 19 (09) 10.12.25 